\title{
Multiple Splicing Factors Are Released from Endogenous Complexes during In Vitro Pre-mRNA Splicing
}

\author{
GREG C. CONWAY,* ADRIAN R. KRAINER, DAVID L. SPECTOR, AND RICHARD J. ROBERTS \\ Cold Spring Harbor Laboratory, Cold Spring Harbor, New York 11724
}

Received 1 June 1989/Accepted 22 August 1989

\begin{abstract}
Pre-mRNA splicing occurs in a macromolecular complex called the spliceosome. Efforts to isolate spliceosomes from in vitro splicing reactions have been hampered by the presence of endogenous complexes that copurify with de novo spliceosomes formed on added pre-mRNA. We have found that removal of these large complexes from nuclear extracts prevents the splicing of exogenously added pre-mRNA. We therefore examined these complexes for the presence of splicing factors and proteins known or thought to be involved in RNA splicing. These fast-sedimenting structures were found to contain multiple small nuclear ribonucleoproteins (snRNPs) and a fragmented heterogeneous nuclear ribonucleoprotein complex. At least two splicing factors other than the snRNPs were also associated with these large structures. Upon incubation with ATP, these splicing factors as well as $\mathrm{U} 1$ and $\mathrm{U} 2 \mathrm{snRNPs}$ were released from these complexes. The presence of multiple splicing factors suggests that these complexes may be endogenous spliceosomes released from nuclei during preparation of splicing extracts. The removal of these structures from extracts that had been preincubated with ATP yielded a splicing extract devoid of large structures. This extract should prove useful in the fractionation of splicing factors and the isolation of native spliceosomes formed on exogenously added pre-mRNA.
\end{abstract}

Several factors have been identified that are necessary for pre-mRNA splicing. The most extensively characterized of these components are the major nucleoplasmic small nuclear ribonucleoprotein (snRNP) particles (U1, U2, U4, U5, and U6; for reviews, see references $23,31,43,51$, and 53). Each snRNP is composed of a unique small nuclear RNA (snRNA), and the RNAs of U1, U2, U4, and U5 possess a trimethyl guanosine cap at their $5^{\prime}$ termini. There is evidence that U4 and U6 snRNAs can reside in a single ribonucleoprotein (RNP) complex $(6,24)$. All snRNPs contain seven common polypeptides, designated $B, B^{\prime}, D, D^{\prime}, E, F$, and $G$. In addition to the common proteins, U1 snRNP contains at least three unique polypeptides, a 70-kilodalton $(\mathrm{kDa})$ protein and proteins designated $A$ and $C$. The U2 snRNP contains at least two unique species, $A^{\prime}$ and $B^{\prime \prime}(6,7,25,42)$.

Evidence for the involvement of snRNPs in splicing derives from the inhibition of in vitro splicing after the addition of snRNP-specific antibodies $(45,55)$ and immunodepletion of $\operatorname{snRNPs}(21,35)$. The selective degradation of snRNAs by oligonucleotide-directed $\mathrm{RNase} \mathrm{H}$ cleavage also indicates that snRNPs are involved in RNA splicing $(1,4,5,30,35)$. In vivo genetic studies in HeLa cells indicate that U1 snRNP bind to $5^{\prime}$ splice sites at least in part by base pairing between the snRNA and pre-mRNA (56). Similar studies with the yeast U2 RNA have shown that U2 snRNP binds to the branch site also in part by base pairing (46). A similar role for base pairing in branch site selection has not yet been shown for mammalian U2 snRNP. Biochemical data have shown that U1 snRNP protects 5' splice sites from nuclease digestion and that $U 2$ snRNP protects the branch point $(4,11,43$, 50). There is also suggestive evidence that U5 snRNP associates with the $3^{\prime}$ splice site; this interaction may be mediated by a polypeptide called the intron-binding protein, which has a binding preference for $3^{\prime}$ splice sites and cofractionates with U5 snRNP $(10,22,54)$. It has recently

* Corresponding author. been shown that purified snRNPs can complement a nuclease-treated extract for splicing (29).

Protein factors other than snRNPs are required for splicing $(30,33,34)$. Biochemical fractionation has identified heat-labile factors required for both the first and second steps of splicing and a heat-stable factor called SF2 (30). None of the non-snRNP splicing factors has been extensively purified. Studies indicate that two proteins, the heterogeneous nuclear RNP (hnRNP) C proteins (C1 and C2), which are major polypeptides bound to hnRNA in vivo, may be involved in splicing (14). In vivo, the $C$ proteins coexist with other proteins in an RNP complex called hnRNP (for reviews, see references 15 and 18). The most predominant proteins in this complex other than the $\mathrm{C}$ proteins are four proteins designated $\mathrm{A} 1, \mathrm{~A} 2, \mathrm{~B} 1, \mathrm{~B} 2$, two closely spaced protein bands of $68 \mathrm{kDa}$, and a 120-kDa protein. Addition of monoclonal antibodies specific for the hnRNP C proteins and immunodepletion of the C-protein complex have been shown to inhibit in vitro splicing (14). The inhibition data suggest that $\mathrm{C}$ proteins or an associated factor(s) are necessary for RNA splicing.

Analysis of in vitro splicing reactions by density gradients or native gels indicates that many factors responsible for RNA splicing are stably bound to pre-mRNA and form a macromolecular complex called the spliceosome. Although these techniques have shown the existence of a stable splicing complex, they give rise to spliceosomes of insufficient purity to allow the identification of protein constituents. Splicing extracts contain endogenous complexes that copurify with spliceosomes formed on exogenously added pre-mRNA. The precise nature of these complexes is unknown. In this study, we examined these endogenous complexes and found that they contain several splicing factors which are released in an ATP-dependent manner. Some of these structures are the remnants of RNP complexes known to exist in vivo. The behavior of these endogenous RNP complexes and the splicing factors they contain suggest strategies that will be useful in the further purification of 
splicing factors and for the isolation of mammalian spliceosomes.

\section{MATERIALS AND METHODS}

Nuclear extract preparation and density gradient fractionation. Nuclear extracts from HeLa cells were prepared as previously described (17). For gradient fractionation, extracts in Dignam buffer D (100 mM KCl, $20 \mathrm{mM} \mathrm{N-2-hydroxy-}$ ethylpiperazine- $N^{\prime}$-2-ethanesulfonic acid [HEPES; pH 7.9], $0.2 \mathrm{mM}$ disodium EDTA, $0.5 \mathrm{mM}$ dithiothreitol) were supplemented to final concentrations of $3.2 \mathrm{mM} \mathrm{MgCl}, 0.5 \mathrm{mM}$ ATP, and $20 \mathrm{mM}$ creatine phosphate or $3.2 \mathrm{mM} \mathrm{MgCl}$ alone and incubated at $30^{\circ} \mathrm{C}$ for $30 \mathrm{~min}$. Nuclear extracts were layered onto 15 to $30 \%$ sucrose gradients in buffer D and centrifuged in an SW28 rotor at $25,000 \mathrm{rpm}$ for $16 \mathrm{~h}$ at $4^{\circ} \mathrm{C}$. Gradients were fractionated with a Buchler autodensiflow IIC and simultaneously scanned at $260 \mathrm{~nm}$ with an ISCO UV monitor. After fractionation, gradient fractions were dialyzed against buffer $D$ to remove sucrose and concentrated with Centriprep centrifugal concentrators (Polysciences). Pooled fractions smaller than 30 S were concentrated to the original extract volume, and fractions larger than $30 \mathrm{~S}$ were reduced to one-fifth the original volume.

RNA synthesis and in vitro splicing. Human $\beta$-globin RNA was synthesized as described by Krainer et al. (32) and capped by the protocol of Konarska et al. (27). In vitro splicing was performed as described by Krainer et al. (32), using $15 \mu$ l of nuclear extract or gradient fractions in a total volume of $25 \mu \mathrm{l}$. Heat-inactivated extracts, micrococcal nuclease-treated extracts, and the cytoplasmic S100 extract were prepared as described by Krainer and Maniatis (30). Complementation experiments were performed with $7.5 \mu \mathrm{l}$ of each fraction.

Immunoprecipitation of purified RNP complexes. For immunoprecipitation, HeLa cells were labeled with $\left[{ }^{35} \mathrm{~S}\right] \mathrm{methi}$ onine and $\left[{ }^{35} \mathrm{~S}\right]$ cysteine. Cells were concentrated to one-fifth the original volume in medium lacking methionine and grown for $30 \mathrm{~min}$ to deplete intracellular methionine pools. Labeled methionine and cysteine $\left({ }^{35} \mathrm{~S}\right.$-Trans; ICN Biochemicals) were added to a final concentration of $50 \mu \mathrm{Ci} / \mathrm{ml}$, and the cells were incubated for $6 \mathrm{~h}$. After labeling, standard nuclear extracts were prepared, fractionated on density gradients, and dialyzed against buffer $D$ to remove sucrose. Antitrimethyl guanosine cap ( $\alpha$-TMG) (29), Y12 (39), 2.31 (3), and 4F4 (13) monoclonal antibodies were coupled to protein A immobilized to Trisacryl (Pierce Chemical Co.). A monoclonal antibody specific for a rotavirus capsid protein (a gift from K. Chan, Cold Spring Harbor Laboratory) was used in control immunoprecipitations. Immobilized antibodies were incubated at $4^{\circ} \mathrm{C}$ for $2 \mathrm{~h}$ with $5.5 \times 10^{6} \mathrm{cpm}$ of pooled gradient fractions less than $30 \mathrm{~S}$ or equal cell equivalents of pooled lower-gradient fractions. Antibody-antigen complexes were washed five times with IP buffer containing 100 $\mathrm{mM} \mathrm{NaCl}, 20 \mathrm{mM}$ HEPES [pH 7.9], and 0.1\% Triton X-100. For analysis of RNA, the beads were suspended in $1 \times \mathrm{PK}$ buffer (150 mM NaCl, $100 \mathrm{mM}$ Tris hydrochloride [pH 7.5], 12.5 mM EDTA, $1 \%$ sodium dodecyl sulfate) containing 200 $\mu \mathrm{g}$ of proteinase $\mathrm{K}$ per $\mathrm{ml}$, incubated at $30^{\circ} \mathrm{C}$ for $15 \mathrm{~min}$, phenol extracted, and ethanol precipitated. For the analysis of proteins, the beads were resuspended in sample buffer and analyzed by sodium dodecyl sulfate-polyacrylamide gel electrophoresis (36).

\section{RESULTS}

Splicing factors exist in fast-sedimenting structures and are released under splicing conditions. Nuclear splicing extracts were fractionated by sucrose gradient sedimentation to resolve endogenous complexes. There were three peaks of material absorbing at an optical density of $260 \mathrm{~nm}\left(\mathrm{OD}_{260}\right)$ (less than 30S, $30 \mathrm{~S}$ to $50 \mathrm{~S}$, and greater than 50S). When these fractions were tested for the ability to splice human $\beta$-globin pre-mRNA in vitro, none was active (Fig. 1B, lanes $3,4,6$, and 8). However, material greater than $30 \mathrm{~S}$ complemented fractions less than $30 \mathrm{~S}$ (Fig. 1B, lanes 5, 7, and 9). Both the $45 \mathrm{~S}$ and greater-than-50S fractions were effective in complementation (lanes 7 and 9). Next, endogenous complexes from extracts preincubated under splicing conditions were examined. This preincubation was at $30^{\circ} \mathrm{C}$ for $30 \mathrm{~min}$ in the presence of $\mathrm{Mg}^{2+}$, ATP, and creatine phosphate. Extracts treated under these conditions will be referred to as +ATP extracts. These conditions reduced the $45 \mathrm{~S}$ peak to one-third of the original $\mathrm{OD}_{260}$ level. A test for splicing activity indicated that fractions less than $30 \mathrm{~S}$ would now splice exogenous pre-mRNA (Fig. 1B, lane 10).

To investigate whether preincubation with ATP is necessary to obtain the partitioning of splicing factors in fractions less than $30 \mathrm{~S}$, we incubated splicing extracts either alone, with $\mathrm{Mg}^{2+}$ (referred to as - ATP extracts), or under splicing conditions (+ ATP extracts) and fractionated them by density gradient sedimentation. Fractions less than and greater than $30 \mathrm{~S}$ were separately pooled and tested for the ability to splice pre-mRNA. We found that in addition to $\mathrm{Mg}^{2+}$, both ATP and creatine phosphate were necessary during the preincubation to obtain splicing activity in fractions less than 30S (data not shown). A low level of splicing activity was seen in less-than-30S fractions after preincubation with $\mathrm{Mg}^{2+}$, and the 45S peak of material was reduced to twothirds of the original $\mathrm{OD}_{260}$ level. These phenomena were probably due to residual ATP in splicing extracts.

snRNPs are among the splicing factors that shift in density gradients. A splicing factor(s) was released from a fastsedimenting complex under splicing conditions (Fig. 1B). The reduction of $\mathrm{OD}_{260}$-absorbing material in the $45 \mathrm{~S}$ peak after incubation suggested that a protein or RNA component was either degraded or released from endogenous complexes. Likely splicing factors with a large $\mathrm{OD}_{260}$ value that might have been released were snRNPs. We therefore examined the distribution of snRNAs in gradient fractions of unincubated splicing extracts, - ATP extracts, and + ATP extracts. In unincubated extracts, most snRNAs existed in large complexes $25 \mathrm{~S}$ or faster (Fig. 2A). U1 snRNAs peaked at the $45 \mathrm{~S}$ position coincident with a smear of highermolecular-weight RNA, whereas U2 peaked at the $30 \mathrm{~S}$ position. Treatment of HeLa cells with actinomycin D 15 min before splicing extract preparation reduced the highmolecular-weight smear to one-fourth the level in untreated cells, indicating that the majority of this material was hnRNA (data not shown). This material was also resistant to DNase digestion. U4, U5, and U6 snRNAs were present in fractions from $25 \mathrm{~S}$ to the bottom of the gradient. Incubation of nuclear extracts with $\mathrm{Mg}^{2+}$ (-ATP extracts) resulted in the shift of a portion of the U1 snRNAs, whereas the other snRNAs and hnRNA remained unaffected (Fig. 2B). Incubation of splicing extracts under splicing conditions resulted in a pronounced shift of $\mathrm{U} 1$ and $\mathrm{U} 2$ snRNAs to the top of gradients, with no effect on the distribution of U4, U5, and U6 snRNAs (Fig. 2C). Residual ATP in splicing extracts may have contributed to the snRNA shift shown in Fig. 2B.

snRNPs remain intact after ATP incubation. Greater-than$30 S$ complexes containing $U 1$ and $U 2$ snRNAs disassembled upon incubation with ATP (Fig. 2). As a result, U1 and U2 snRNAs remained at the top of gradients and existed either 

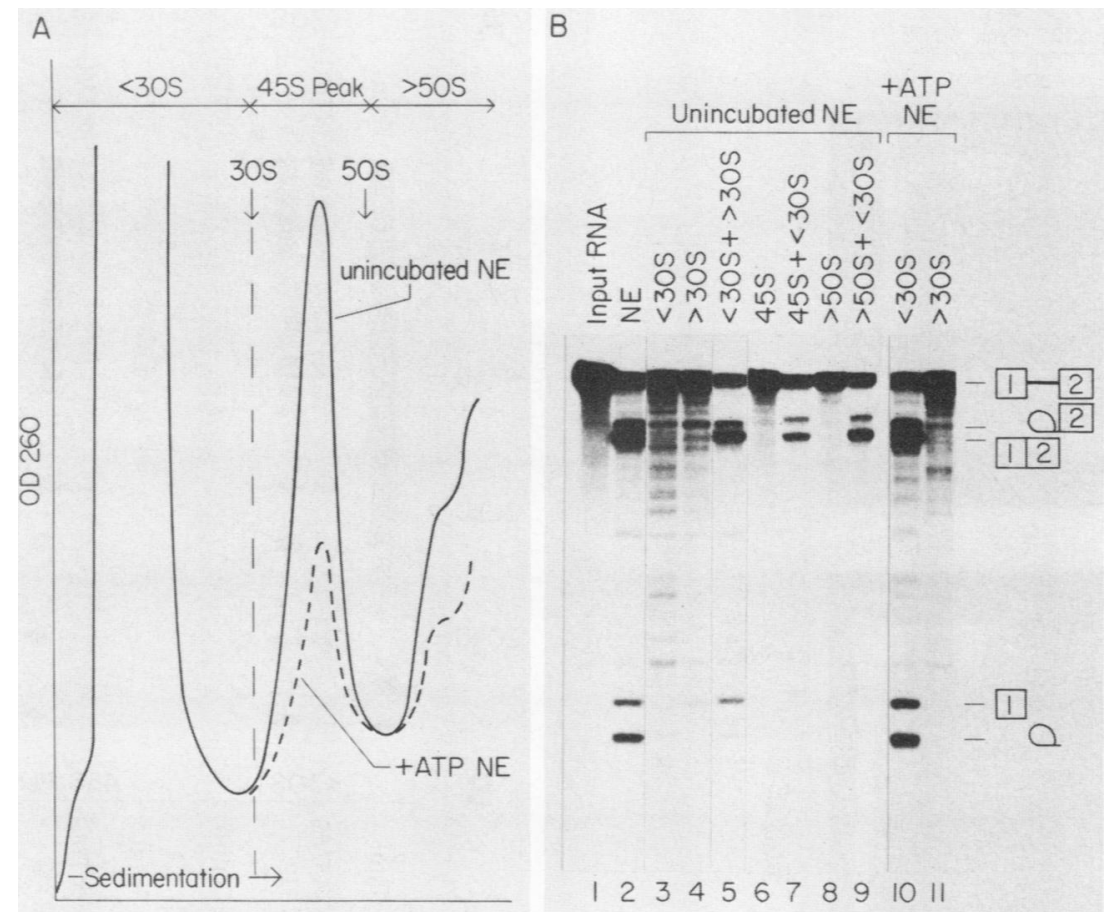

FIG. 1. Density gradient fractionation of splicing extracts and assay of splicing activity in the resulting fractions. (A) Splicing extracts (NE) either unincubated or incubated under splicing conditions at $30^{\circ} \mathrm{C}$ for $30 \mathrm{~min}$ with $\mathrm{Mg}^{2+}$, creatine phosphate, and ATP (+ ATP NE) were fractionated on 15 to $30 \%$ sucrose gradients. After centrifugation, the gradients were fractionated and scanned for $\mathrm{OD}_{260^{-}}$-absorbing material. The $30 \mathrm{~S}$ and $50 \mathrm{~S}$ positions of the gradients were determined by sedimentation of Escherichia coli ribosomal subunits in parallel gradients. (B) Pools of gradient fractions shown in panel A were tested for splicing activity and for the ability to complement one another.

as protein-free snRNAs or as snRNP particles. To determine whether snRNP proteins remain associated with snRNA after incubation, immunoprecipitations were performed with $\left[{ }^{35}\right.$ S]methionine-labeled splicing extracts. If snRNPs are intact, then $\alpha$-TMG monoclonal antibody (29), which recognizes the unique cap structure of $\mathrm{U} 1, \mathrm{U} 2, \mathrm{U} 4$, and $\mathrm{U} 5$ snRNAs, should precipitate snRNP polypeptides. $\alpha$-TMG antibody precipitated the $A, B, B^{\prime}$, and $C$ snRNP polypeptides in less-than-30S and $45 \mathrm{~S}$ gradient fractions from - ATP extracts (Fig. 3A), indicating that these snRNP polypeptides were bound to both fast- and slow-sedimenting snRNA species. Similarly, the Y12 monoclonal antibody, which recognizes $B, B^{\prime}$, and $D_{\text {proteins, precipitated the } A \text { through }}$ $C$ polypeptides and showed a roughly equal abundance of these proteins in $45 \mathrm{~S}$ and less-than-30S fractions. This result correlates well with the results presented in Fig. 2B, which shows an equal abundance of snRNAs in $45 \mathrm{~S}$ and lessthan-30S fractions. The increased amounts of $B$ and $B^{\prime}$ polypeptides precipitated with $\mathrm{Y} 12$ as compared with $\alpha$ TMG antibodies in fractions less than $30 \mathrm{~S}$ was probably due to precipitation of RNA-free $B$ and $B^{\prime}$ polypeptides before their assembly into snRNP particles (19). The difference in the amounts of precipitated core proteins seen with $\alpha$-TMG and Y12 antibodies in the $45 \mathrm{~S}$ fractions may have been due to decreased accessibility of the 5' cap of these snRNAs to the $\alpha$-TMG antibody.

Although in - ATP extracts the common snRNP polypeptides remain associated with snRNAs, incubation with ATP might induce a dissociation of snRNPs from snRNA. This was not the case for the A, B, B', and C proteins (Fig. 3B). Even after ATP incubation and the abundant appearance of snRNAs in less-than-30S fractions, these proteins remained precipitable with $\alpha$-TMG and Y12 monoclonal antibodies.
These results indicate that $45 \mathrm{~S}$ snRNPs disaggregate into individual snRNP particles rather than completely dissociating into RNA and proteins.

In addition to the common proteins, snRNPs contained higher-molecular-weight proteins (bracketed in Fig. 3A). These proteins appeared less abundant relative to the common polypeptides by Coomassie staining than by ${ }^{35} \mathrm{~S}$ labeling, possibly because of their rapid turnover and methionine content. These proteins were specifically associated with snRNP particles, as shown by their exclusive precipitation with two snRNP-specific antibodies (Y12 and $\alpha$-TMG) and their absence with an antibody that recognizes hnRNP C proteins (4F4 antibody) and a control monoclonal antibody against a rotaviral capsid protein. Close scrutiny of these high-molecular-weight proteins indicated differences in the polypeptide composition of less-than-30S and greater-than$30 \mathrm{~S}$ snRNPs. In addition, ATP incubation affected the abundance of some of these proteins relative to the levels of the common snRNP polypeptides. These phenomena are under further investigation.

The hnRNP C proteins do not shift to upper-gradient fractions upon incubation under splicing conditions. To determine whether the hnRNP C proteins shift in density gradients under splicing conditions, immunoprecipitations using the 4F4 monoclonal antibody specific for the hnRNP C proteins were performed. Most of the $\mathrm{C} 1$ and $\mathrm{C} 2$ proteins in - ATP extracts resided in fractions greater than $30 \mathrm{~S}$ (Fig. 3A). Upon incubation with ATP, a portion of the $C$ proteins in fractions greater than $50 \mathrm{~S}$ shifted to the $45 \mathrm{~S}$ fraction (Fig. 3B). Gradient fractions less than $30 \mathrm{~S}$ contained little immunoprecipitable $\mathrm{C}$ protein. Immunoprecipitation recovered not only the $C$ proteins but also several higher-molecularsize species, among them doublets at approximately $68 \mathrm{kDa}$ 


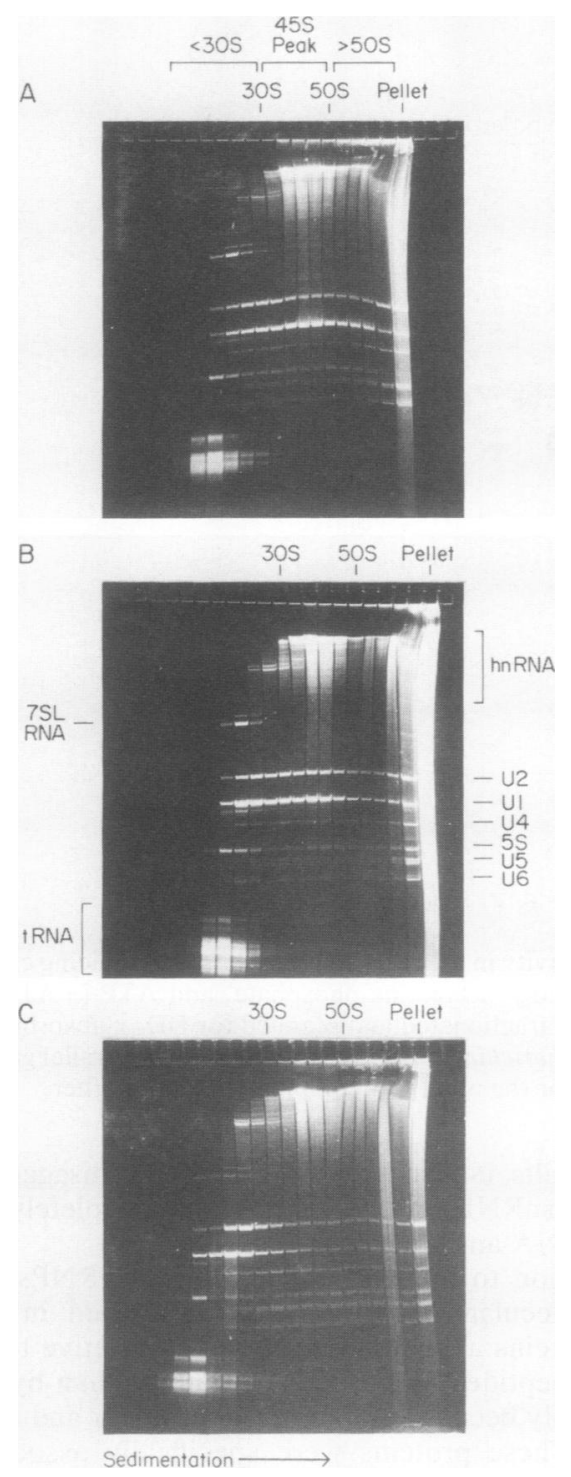

FIG. 2. Sedimentation analysis of snRNAs in splicing extracts. Unincubated splicing extracts (A), extracts incubated with $\mathbf{M g}^{2+}$ alone $(B)$, and extracts incubated under splicing conditions $(C)$ were fractionated on 15 to $30 \%$ sucrose gradients. The RNA in each fraction was analyzed on $8 \%$ denaturing gels and visualized by ethidium staining.

and at $120 \mathrm{kDa}$. The coprecipitation of these proteins was most prominent in fractions greater than 50S.

Heat-labile splicing factors and SF2 shift in density gradients. We examined the sedimentation behavior of splicing factors other than the snRNPs. Gradient fractions were assayed for the presence of heat-labile factors by complementation of a heat-inactivated extract and for SF2 (30) by complementation of an $\mathrm{S} 100$ extract missing this factor. Fractions greater than $30 \mathrm{~S}$ from - ATP extracts contained active heat-labile factors (Fig. 4, lane 3) and SF2 (lane 7) but were missing from upper-gradient fractions (lanes 2 and 6). In unincubated extracts, heat-labile factors and SF2 were also exclusively found in lower-gradient fractions (data not shown). When nuclear extracts were preincubated under splicing conditions, heat-labile factors, especially the heatlabile factor required for the second step of splicing desig-

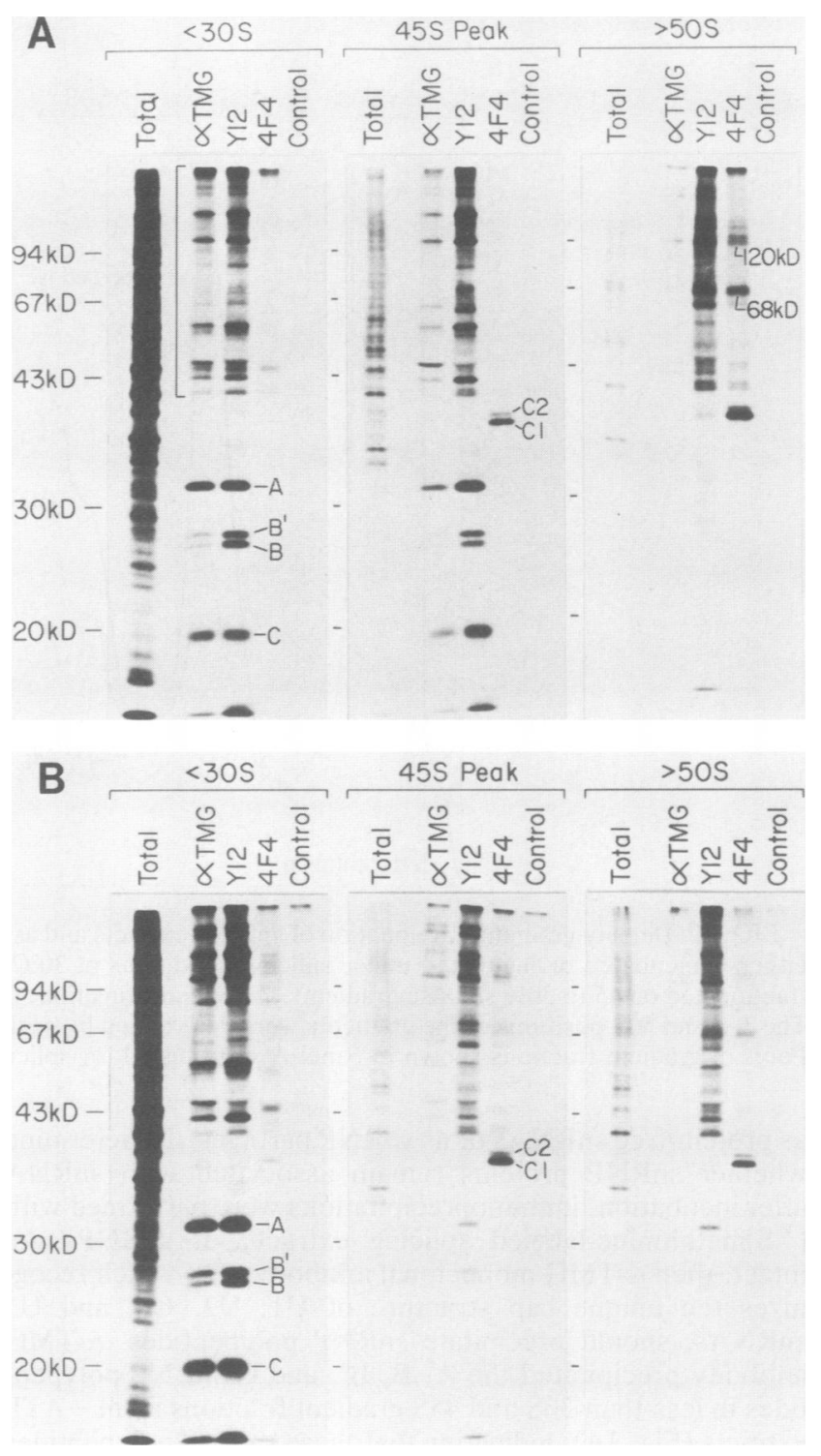

FIG. 3. Immunoprecipitation of snRNPs and hnRNPs from fractionated nuclear extracts. HeLa cells were labeled in vivo with $\left[{ }^{35}\right.$ S]methionine, and nuclear extracts were prepared. Splicing extracts were incubated either with $\mathbf{M g}^{2+}$ alone (A) or under splicing conditions (B). Extracts were then fractionated on sucrose gradients, and equal cell equivalents of pooled fractions were used in immunoprecipitations with $\alpha$-TMG (recognizes the cap structure of U1 to U5 snRNAs), Y12 (recognizes B, B', and D snRNP proteins), 4F4 (recognizes the hnRNP C proteins), and a control antibody (recognizes a rotavirus capsid protein). The lanes marked Total contained $1 / 50$ the protein in fractions used for immunoprecipitation. Molecular size markers are indicated on the left. The vertical bracket in panel A marks the position of high-molecular-weight snRNP proteins.

nated SF3 (30), and SF2 were reduced in lower-gradient fractions (lanes 4 and 8 ). These factors were now present at the top of gradients, since these upper-gradient fractions were fully competent for splicing (Fig. 1B, lane 10).

Cleared extracts can be used to identify spliceosomal components. To demonstrate the utility of cleared splicing extracts, we analyzed the snRNA composition of spliceosomes. Splicing reactions were performed with cleared 


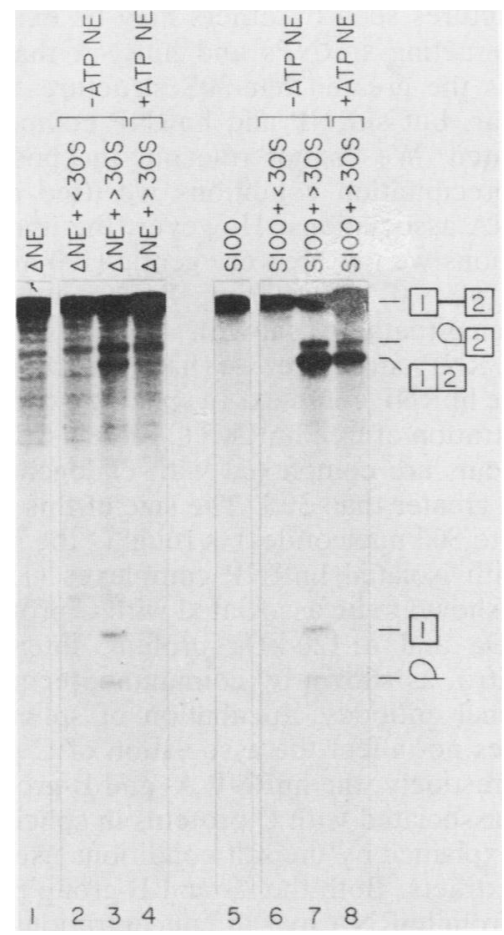

FIG. 4. Assay for SF2 and heat-labile factors in gradient fractions. Splicing extracts incubated either with $\mathbf{M g}^{2+}$ alone (-ATP NE) or under splicing conditions (+ATP NE) were fractionated on sucrose gradients, and pooled fractions were assayed for complementation of a heat-inactivated extract $(\Delta \mathrm{NE}$; lanes 2 to 4$)$ or an S100 extract lacking SF2 (lanes 6 to 8 ). Reactions with heatinactivated extract and with an S100 extract are shown in lanes 1 and 5 , respectively.

extracts and human $\beta$-globin pre-mRNA and subjected to sucrose gradient sedimentation. A mock splicing reaction lacking exogenous splicing substrate did not result in the formation of snRNP complexes that sedimented into lowergradient fractions (Fig. 5A). However, addition of premRNA caused a shift of U1, U2, U5, and U6 snRNAs into the gradient (compare lanes 17 of Fig. 5A and B). The sedimentation of these snRNPs into this region was coincident with the presence of pre-mRNA and splicing intermediates (Fig. 5C). Although the migration of U4 snRNA was shifted into the gradient by addition of pre-mRNA, this snRNP did not peak with splicing intermediates. This observation is consistent with reports that $\mathrm{U} 4 \mathrm{snRNP}$ dissociates from the spliceosome during RNA splicing $(12,28,37,48)$.

\section{DISCUSSION}

We have assayed RNP complexes found in splicing extracts for the ability to splice exogenous pre-mRNA as well as for the presence of specific splicing factors. We have found that splicing extracts contain at least two types of RNP complexes larger than $30 \mathrm{~S}$; one of these structures contains snRNPs, whereas the other is an hnRNP complex. The majority of snRNPs in unincubated extracts sediment faster than 25S. The nature of these large snRNP complexes is unknown. However, they do not appear to result from interactions with hnRNA. Incubation with $\mathrm{Mg}^{2+}$, ATP, and creatine phosphate converts almost all of the U1 and U2 snRNPs into slow-sedimenting structures. There are subtle differences in the high-molecular-weight polypeptide compo-

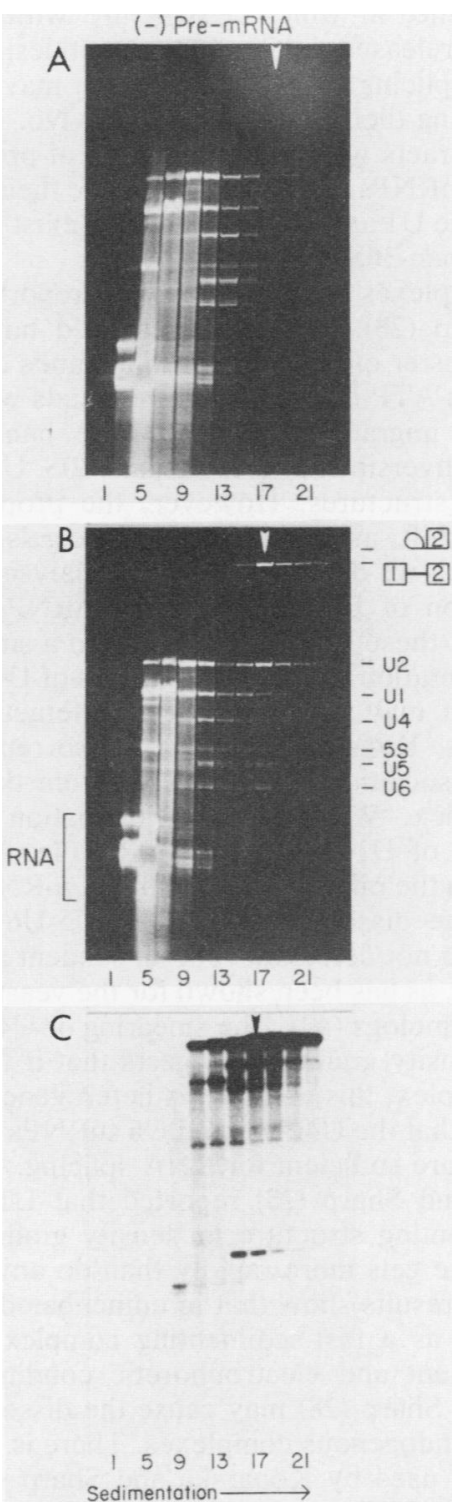

FIG. 5. Sedimentation analysis of snRNPs in splicing reactions with cleared nuclear extracts. One-hour splicing reactions $(2.5 \mathrm{ml}$, total volume) containing either no RNA (A) or $2.5 \mu \mathrm{g}$ of ${ }^{32} \mathrm{P}$-labeled human $\beta$-globin pre-mRNA (B) were performed with cleared extracts. Reactions were analyzed on 15 to $30 \%$ sucrose gradients and fractionated, and the RNA in odd-numbered fractions was analyzed on $8 \%$ denaturing gels. Compare lanes 17 of panels A and B (arrowhead). One-fifth of the RNA in each odd-numbered fraction was analyzed on $5 \%$ denaturing gels and autoradiographed $(\mathrm{C})$.

sitions of fast- and slow-sedimenting snRNPs. ATP incubation also affects the abundance of these proteins relative to the abundance of the common snRNP proteins. A $260-\mathrm{kDa}$ protein that is associated with snR7, the yeast U5 homolog, has recently been identified (40). The mammalian homolog of this protein may be represented among the high-molecularweight species identified in Fig. 3.

snRNPs may be dynamic structures consisting of a stable core of several polypeptides to which other polypeptides are more loosely or transiently associated. Some proteins might be necessary for pre-mRNA binding, while others might be required for exon alignment, cleavage, ligation and, in some instances, alternative splicing. Such a model is reminiscent 
of the ribosome, in which a structure with a fixed core acquires and releases auxiliary polypeptides. snRNPs isolated during splicing extract preparation may be heterogeneous, reflecting their dynamic state in vivo. Preincubation of splicing extracts without the addition of pre-mRNA may synchronize snRNPs at a point just before their participation in splicing. The $U 1$ and $U 2$ snRNPs may exist in this primed state as less-than-30S structures.

snRNP complexes or aggregates were reported by Konarska and Sharp (28). These studies used native gels and indicated a cluster of slowly migrating bands containing U2 snRNA. Upon ATP incubation, these bands were shifted to more rapidly migrating species. These band shifts may reflect the conversion of greater-than-30S U2 snRNPs to less-than-30S structures. However, the proportion of U2 snRNPs that shift, as indicated by native gels, is much less than that which we detect. Native gel analysis also showed the comigration of U4, U5, and U6 snRNPs, and it was suggested that these snRNPs can exist in a single complex. The cosedimentation in sucrose gradients of U4, U5, and U6 that we report may be the result of interactions between these particles. Konarska and Sharp also report the ATPdependent dissociation of U4 snRNP from this U4-U5-U6 snRNP complex. Whereas ATP incubation results in a dramatic shift of U1 and U2 snRNPs (Fig. 2), we do not detect shifts in the migration of the other snRNPs that might result from the dissociation of a U4-U5-U6 complex. In addition we do not detect an ATP-dependent association of these snRNPs, as has been shown for the yeast U4, U5, and U6 snRNA homologs (40). The smearing of U4, U5, and U6 across our density gradients suggests that if these snRNPs exist in a complex, this complex is heterogeneous. Interestingly, we find that the U4, U5, and U6 snRNPs that sediment less than $30 \mathrm{~S}$ are sufficient for RNA splicing.

Konarska and Sharp (28) reported that U1 snRNP is a slowly sedimenting structure in density gradients and migrates in native gels more rapidly than do any of the other snRNPs. Our results show that in unincubated extracts, U1 snRNP exists as a fast-sedimenting complex. We believe that the gradient and electrophoretic conditions used by Konarska and Sharp (28) may cause the dissociation of U1 snRNP from endogenous complexes. There is evidence that the conditions used by Konarska and Sharp weaken interactions of U1 snRNP with other components of the splicing apparatus, since their conditions fail to detect U1 snRNP in spliceosomes. On the other hand, different electrophoretic conditions can demonstrate the presence of U1 snRNP in spliceosomes (57). This destabilizing effect may extend to interactions between U1 snRNP and the endogenous complexes of splicing extracts, explaining the discrepancy between our results and those of Konarska and Sharp (28).

The sedimentation of snRNPs in lower-gradient fractions reported in this paper is similar to that reported earlier by Lerner et al. (38) and Spector et al. (52). The fast sedimentation of snRNPs reported by others was interpreted to be the result of an interaction between snRNPs and hnRNA. The similar phenomena that we observe in splicing extracts originally led us to the same conclusion. However, immunoprecipitations with anti-snRNP and anti-hnRNP C-protein antibodies suggest that in splicing extracts snRNPs and hnRNA reside in different complexes. The studies of Lerner et al. and Spector et al. were performed with a nuclear extract that was not subjected to high salt and was produced by sonication of nuclei. This technique is more likely to protect and release snRNP-hnRNA complexes than is the high-salt extractions used to make splicing extracts. There- fore, the structures seen by others may be extracted complexes of interacting snRNPs and hnRNA that existed in vivo, whereas the greater-than-30S structures we observe may be similar, but snRNP and hnRNP components have been dissociated. We cannot rule out the possibility that the immunoprecipitation conditions we used may disrupt snRNP-hnRNA associations. However, the immunoprecipitation conditions we use are very gentle $(100 \mathrm{mM} \mathrm{NaCl}, 20$ mM HEPES [pH 8.0], 0.1\% Triton X-100) and are compatible with splicing (data not shown).

The other RNP structure we have characterized is a remnant of the hnRNP complex. In splicing extracts, there is a low concentration of free hnRNP C proteins. The majority of these proteins are complexed with endogenous hnRNA and sediment greater than $30 \mathrm{~S}$. The size of this endogenous hnRNA (500 to 800 nucleotides) is roughly the same as that associated with isolated hnRNP complexes $(13,41)$. Two polypeptides shown to be associated with $\mathrm{C}$ proteins in vivo (13), a $68-\mathrm{kDa}$ and a $120-\mathrm{kDa}$ protein, interact with $\mathrm{C}$ proteins in vitro, as shown by coimmunoprecipitation with 4F4 monoclonal antibody. Incubation of splicing extracts with ATP does not affect the association of $C$ protein with hnRNA. Interestingly, the hnRNP A- and B-group polypeptides are not associated with $\mathrm{C}$ proteins in splicing extracts. This can be explained by the salt conditions used in preparing splicing extracts. Both the A- and B-group polypeptides are released from hnRNA by salt concentrations $200 \mathrm{mM}$ or higher (2), roughly the concentration used during splicing extract preparation. It is interesting that these proteins do not reassociate with hnRNA after dialysis to low-salt conditions. These proteins may either remain soluble or form insoluble helical filaments, an alternate structural form of these proteins (41). These filaments would be removed during one of the centrifugation steps in extract preparation.

We have also found that protein factors necessary for splicing, namely, heat-labile factors and SF2, shift to uppergradient fractions after ATP incubation. It is not known whether these factors in unincubated extracts are associated with greater-than-30S snRNPs, C-protein complexes, both, or other structures. A recent study has shown that SF2 is not associated with snRNPs immunopurified from unincubated extracts (29). It is possible that after incubation, heat-labile factors and SF2 associate with less-than-30S snRNPs.

The work of Reed et al. (49) also indicates that splicing extracts contain endogenous RNP particles. Using gel filtration chromatography, they isolated fractions containing spliceosomes formed on exogenously added RNA. In these fractions, they observed $40-$ to $60-\mathrm{nm}$ particles that were micrococcal nuclease sensitive, and these fractions contained snRNPs and endogenous hnRNA. These particles were observed whether or not pre-mRNA was added to extracts, indicating that the particles arose predominantly from endogenous material. The characteristics of the particles described by Reed et al. are similar to those of the RNPs we have isolated. Density gradient centrifugation may accomplish a fractionation similar to that achieved by gel filtration chromatography. The structures described by Reed et al., as judged by quantitation from electron microscopy, seem to form only in the presence of ATP. In contrast, we find that the majority of $50 \mathrm{~S}$ to $60 \mathrm{~S}$ snRNPs, those being mainly $\mathrm{U} 1$ and $\mathrm{U} 2$, are converted to less-than-30S structures by ATP. After ATP incubation, the majority of material that remains is the hnRNP complex and a small fraction of the snRNPs. This material may be identical to that seen by Reed et al.

Efforts to isolate yeast spliceosomes have also been com- 
plicated by the presence of material in splicing extracts that cosediment with spliceosomes formed on exogenously added pre-mRNA. It was noted by Brody and Abelson (9) that the sedimentation rate of the yeast spliceosome is influenced by monovalent cation concentration. Taking advantage of this phenomena, Clark et al. (16) have developed a salt-shift purification scheme for isolating yeast spliceosomes. Splicing reactions are first sedimented in high salt containing glycerol gradients. The spliceosome peak is then sedimented in a low-salt-containing gradient. In each gradient, the spliceosome peaks in different fractions as a result of the salt effect, with the net result of purifying spliceosomes from contaminating structures. By use of this method, spliceosomes have been purified sufficiently to allow ultrastructural analysis of complexes formed on exogenously added pre-mRNA. Conceptually, there are parallels between the salt-shift scheme and the preclearing of splicing extracts that we describe. Both methods try to enrich for spliceosomes formed on added pre-mRNA by the removal of endogenous complexes.

In conclusion, mammalian splicing extracts contain endogenous complexes that possess splicing factors. These factors are released during in vitro splicing reactions, and this release is probably a prerequisite for the splicing of exogenous pre-mRNA. These endogenous complexes may be spliceosomes or portions of that complex released from nuclei during extract preparation. However, barring a functional test which determines that these endogenous structures splice endogenous RNA, we do not feel that the term spliceosome should be attributed to the structures we have seen. It cannot be concluded that endogenous RNP complexes of nuclear extracts are native structures unless this hypothesis is tested by a functional assay. The hnRNP complex has undergone partial dissociation during extract preparation, and large snRNP complexes could result from artifactual aggregation. Despite this uncertain etiology, the phenomena we report should have important implications for the purification of splicing factors. Prior ATP incubation may facilitate the separation of splicing factors from contaminants. The use of extracts cleared of endogenous complexes should be valuable in the isolation of native spliceosomes, since splicing reactions with this extract will contain only a single large structure, the splicing complex formed on exogenous pre-mRNA. We have demonstrated the utility of this method in the analysis of the snRNA components in spliceosomes. A detailed analysis of the polypeptide composition of spliceosomes is in progress.

\section{ACKNOWLEDGMENTS}

We thank Kit Chan and members of R.J.R.'s group for helpful discussions and Jim Duffy and David Greene for preparation of figures. We thank David Frendewey and Denise Roberts for critical reading of the manuscript. We also thank J. Steitz, S. Hoch, G. Dreyfuss, and $\mathrm{K}$. Chan for gifts of antibodies.

This work was supported by Public Health Service grant CA13106 from the National Cancer Institute, American Cancer Society grant NP-619 (D.L.S.), and the Robertson Research Fund (A.R.K.). G.C.C. is an American Cancer Society postdoctoral fellow (grant PF-3237).

\section{LITERATURE CITED}

1. Berget, S. M., and B. L. Robberson. 1986. U1, U2, and U4/U6 small nuclear ribonucleoproteins are required for in vitro splicing but not polyadenylation. Cell 46:691-696.

2. Beyer, A. L., M. E. Christensen, B. W. Walker, and W. M. LeStourgeon. 1977. Identification and characterization of the packaging proteins of core $40 \mathrm{~S}$ hnRNP particles. Cell 11:
127-138.

3. Billings, P. B., R. W. Allen, F. C. Jensen, and S. O. Hoch. 1982. Anti-RNP monoclonal antibody derived from a mouse strain with lupus-like autoimmunity. J. Immunol. 128:1176-1180.

4. Black, D. L., B. Chabot, and J. A. Steitz. 1985. U2 as well as U1 small nuclear ribonucleoproteins are involved in pre-mRNA splicing in vitro. Cell 42:737-750.

5. Black, D. L., and J. A. Steitz. 1986. Pre-mRNA splicing in vitro requires intact U4/U6 small nuclear ribonucleoprotein. Cell 46:697-704.

6. Bringman, P., B. Appel, J. Rinke, R. Reuter, H. Theissen, and R. Luhrmann. 1984. Evidence for the existence of snRNAs U4 and U6 in a single ribonucleoprotein complex and for their association by intermolecular base pairing. EMBO J. 3:1357-1363.

7. Bringman, P., and R. Luhrmann. 1986. Purification of the individual snRNPs U1, U2, U5 and U4/U6 from HeLa cells and characterization of their protein constituents. EMBO J. 5: 3509-3516.

8. Bringman, P., J. Rinde, B. Appel, R. Reuter, and R. Luhrmann. 1983. Purification of snRNPs U1, U2, U4, U5, and U6 with 2,2,7-trimethylguanosine antibody and definition of their constituent proteins reacting with anti-SM and anti-(U1)RNP antisera. EMBO J. 2:1129-1135.

9. Brody, E., and J. Abelson. 1985. The "spliceosome": yeast pre-messenger RNA associates with a $40 \mathrm{~S}$ complex in a splicingdependent reaction. Science 228:963-967.

10. Chabot, B., D. L. Black, D. M. LeMaster, and J. A. Steitz. 1985. The $3^{\prime}$ splice site of pre-messenger RNA is recognized by a small nuclear ribonucleoprotein. Science 230:1344-1349.

11. Chabot, B., and J. A. Steitz. 1987. Multiple interactions between the splicing substrate and small nuclear ribonucleoproteins in spliceosomes. Mol. Cell. Biol. 7:281-293.

12. Chen, S. C., and J. Abelson. 1987. Spliceosome assembly in yeast. Genes Dev. 1:1014-1027.

13. Choi, Y. D., and G. Dreyfuss. 1984. Isolation of the heterogeneous nuclear ribonucleoprotein complex (hnRNP): a unique supramolecular assembly. Proc. Natl. Acad. Sci. USA 81: 7471-7475.

14. Choi, Y. D., P. J. Grabowski, P. A. Sharp, and G. Dreyfuss. 1986. Heterogeneous nuclear ribonucleoproteins: role in RNA splicing. Science 231:534-539.

15. Chung, S. Y., and J. Wooley. 1986. Set of novel, conserved proteins fold pre-messenger RNA into ribonucleosomes. Proteins 1:195-210.

16. Clark, M. W., S. Goelz, and J. Abelson. 1988. Electron microscopic identification of the yeast spliceosome. EMBO J. 7: 3829-3836.

17. Dignam, J., R. M. Lebovitz, and R. G. Roeder. 1983. Accurate transcription initiation by RNA polymerase II in a soluble extract from isolated mammalian nuclei. Nucleic Acids Res. 11:1475-1489.

18. Dreyfuss, G. 1986. Structure and function of nuclear and cytoplasmic ribonucleoprotein particles. Annu. Rev. Cell Biol. 2: $459-498$.

19. Feeney, R. J., R. A. Sauterer, J. L. Feeney, and G. W. Zieve. 1989. Cytoplasmic assembly and nuclear accumulation of mature small nuclear ribonucleoprotein particles. J. Biol. Chem. 264:5776-5783.

20. Fisher, D. E., G. E. Conner, W. H. Reeves, R. Wisniewolski, and G. Blobel. 1985. Small nuclear ribonucleoprotein particle assembly in vivo: demonstration of a 6S RNA-free core precursor and posttranslational modification. Cell 42:751-758.

21. Frendewey, D., and W. Keller. 1985. Stepwise assembly of a pre-mRNA splicing complex requires U-snRNPs and specific intron sequences. Cell 42:355-367.

22. Gerke, V., and J. A. Steitz. 1986. A protein associated with small nuclear ribonucleoprotein particles recognizes the 3' splice site of premessenger RNA. Cell 47:973-984.

23. Green, M. R. 1986. Pre-mRNA splicing. Annu. Rev. Genet. 20:671-708.

24. Hashimoto, C., and J. A. Steitz. 1984. U4 and U6 RNAs conexist in a single small nuclear ribonucleoprotein particle. Nucleic Acids Res. 12:3283-3293. 
25. Hinterberger, M., I. Pettersson, and J. A. Steitz. 1983. Isolation of small nuclear ribonucleoproteins containing U1, U2, U4, U5 and U6 RNAs. J. Biol. Chem. 258:2604-2613.

26. Kinlaw, C. S., B. L. Robberson, and S. M. Berget. 1983. Fractionation and characterization of human small nuclear ribonucleoproteins containing U1 and U2 RNAs. J. Biol. Chem. 258:7181-7189.

27. Konarska, M. M., R. A. Padgett, and P. A. Sharp. 1984. Recognition of cap structure in splicing in vitro of mRNA precursors. Cell 38:731-736.

28. Konarska, M. M., and P. A. Sharp. 1987. Interactions between small nuclear ribonucleoprotein particles in formation of spliceosomes. Cell 49:763-774.

29. Krainer, A. R. 1988. Pre-mRNA splicing by complementation with purified human U1, U2, U4/U6 and U5 snRNPs. Nucleic Acids Res. 16:9415-9429.

30. Krainer, A. R., and T. Maniatis. 1985. Multiple factors including the small nuclear ribonucleoproteins $\mathrm{U} 1$ and $\mathrm{U} 2$ are necessary for pre-mRNA splicing in vitro. Cell 42:725-736.

31. Krainer, A. R., and T. Maniatis. 1988. RNA splicing, p. 131194. In B. D. Hames and D. M. Glover (ed.), Transcription and splicing. IRL Press, Washington, D.C.

32. Krainer, A. R., T. Maniatis, B. Ruskin, and M. R. Green. 1984 Normal and mutant human $\beta$-globin pre-mRNAs are faithfully and efficiently spliced in vitro. Cell 36:993-1005.

33. Kramer, A., M. Frick, and W. Keller. 1987. Separation of multiple components of HeLa cell nuclear extracts required for pre-messenger RNA splicing. J. Biol. Chem. 262:17630-17640.

34. Kramer, A., and W. Keller. 1985. Purification of a protein required for the splicing of pre-mRNA and its separation from the lariat debranching enzyme. EMBO J. 4:3571-3581.

35. Kramer, A., W. Keller, B. Appel, and R. Luhrmann. 1984. The 5 ' terminus of the RNA moiety of U1 small nuclear ribonucleoprotein particles is required for the splicing of messenger RNA precursors. Cell 38:299-307.

36. Laemmli, U. K. 1970. Cleavage of structural proteins during the assembly of the head of bacteriophage T4. Nature (London) 227:680-685.

37. Lamond, A. I., M. M. Konarska, P. J. Grabowski, and P. A. Sharp. 1988. Spliceosome assembly involves the binding and release of U4 small nuclear ribonucleoprotein. Proc. Natl. Acad. Sci. USA 85:411-415.

38. Lerner, M. R., J. A. Boyle, S. M. Mount, S. L. Wolin, and J. A. Steitz. 1980. Are snRNPs involved in splicing? Nature (London) 283:220-224.

39. Lerner, E. A., M. R. Lerner, C. A. Janeway, Jr., and J. A. Steitz. 1981. Monoclonal antibodies to nucleic acid containing cellular constituents: probes for molecular biology and autoimmune disease. Proc. Natl. Acad. Sci. USA 78:2737-2741.

40. Lossky, M., G. J. Anderson, S. P. Jackson, and J. Beggs. 1987. Identification of a yeast snRNP protein and detection of snRNPsnRNP interactions. Cell 51:1019-1026.

41. Lothstein, L., H. P. Arenstorf, J. C. Wooley, S. Y. Chung, B. W.
Walker, and W. M. LeStourgeon. 1985. The general organization of protein and RNA in HeLa 40S ribonucleoprotein particles. J. Cell Biol. 100:1570-1581.

42. Luhrmann, R. 1988. snRNP proteins, p. 71-99. In M. L. Birnstiel (ed.), Structure and function of major and minor small nuclear ribonucleoprotein particles. Springer-Verlag KG Berlin.

43. Maniatis, T., and R. Reed. 1987. The role of small nuclear ribonucleoprotein particles in pre-mRNA splicing. Nature (London) 325:673-678.

44. Mount, S. M., I. Pettersson, M. Hinterberger, A. Karmas, and J. A. Steitz. 1983. The U1 small nuclear RNA-protein complex selectively binds a 5' splice site in vitro. Cell 33:509-518.

45. Padgett, R. A., S. M. Mount, J. A. Steitz, and P. A. Sharp. 1983. Splicing of messenger RNA precursors is inhibited by antisera to small nuclear ribonucleoproteins. Cell 35:101-107.

46. Parker, R., P. G. Siliciano, and C. Guthrie. 1987. Recognition of the TACTAAC box during mRNA splicing in yeast involves base pairing to the U2-like snRNA. Cell 49:229-239.

47. Perkins, K. K., H. M. Furneaux, and J. Hurwitz. 1986. RNA splicing products formed with isolated fractions from HeLa cells are associated with fast sedimenting complexes. Proc. Natl. Acad. Sci. USA 83:887-891.

48. Pikielny, C. W., and M. Rosbash. 1986. Specific small nuclear RNAs are associated with yeast spliceosomes. Cell 45:869-877.

49. Reed, R., J. Griffith, and T. Maniatis. 1988. Purification and visualization of native spliceosomes. Cell 53:949-961.

50. Ruskin, B., P. D. Zamore, and M. R. Green. 1988. A factor, $\mathrm{U} 2 \mathrm{AF}$, is required for $\mathrm{U} 2$ snRNP binding and splicing complex assembly. Cell 52:207-219.

51. Sharp, P. A. 1987. Splicing of messenger RNA precursors. Science 235:766-771.

52. Spector, D. L., W. H. Schrier, and H. Busch. 1983. Immunoelectron microscopic localization of snRNPs. Biol. Cell 49:1-10.

53. Steitz, J. A., S. L. Wolin, J. Rinke, I. Pettersson, S. M. Mount, E. A. Lerner, M. Hinterberger, and E. Gottlieb. 1983. Small ribonucleoproteins from eukaryotes: structures and roles in RNA biogenesis. Cold Spring Harbor Symp. Quant. Biol. 47:893-900.

54. Tazi, J., C. Alibert, J. Temsamani, I. Receillaud, G. Cathala, C. Brunel, and P. Jeanteur. 1986. A protein that specifically recognizes the $3^{\prime}$ splice site of mammalian pre-mRNA introns is associated with a small nuclear ribonucleoprotein. Cell 47: 755-766.

55. Yang, V. W., M. R. Lerner, J. A. Steitz, and S. J. Flint. 1981. A small nuclear ribonucleoprotein is required for splicing of adenoviral early RNA sequences. Proc. Natl. Acad. Sci. USA 78:1371-1375.

56. Zhuang, Y., and A. M. Weiner. 1986. A compensatory base change in U1 snRNA suppresses a $5^{\prime}$ splice site mutation. Cell 46:827-835.

57. Zillman, M., M. L. Zapp, and S. M. Berget. 1988. Gel electrophoretic isolation of splicing complexes containing U1 small nuclear ribonucleoprotein particles. Mol. Cell. Biol. 8:814-821. 